\title{
Gastropericardial fistula
}

\section{complicating an adenocarcinoma of the stomach}

AS Shaik
MBChB (Natal), FCS (SA)
B Singh
FCS (SA)
J Maharajh
FFRad (SA)*
J Moodley
FCS (SA)
Department of General Surgery and *
Radiology, University of Natal Medical
School, Durban, South Africa

\section{Introduction}

Of the various conditions affecting the stomach, gastric cancer invariably imparts a fatal outcome, death being usually due to the indolent yet relentless malignant proeess. Rarely a complication such as a gastropericardial fistula may be the cause of the fatal event. Gastropericardial fistula with the resultant pneumopericardium is an extremely rare condition with a high mortality. ${ }^{1,2,3}$ This condition was first described by Hallin in $1891 .{ }^{4}$ To date 57 cases of gastropericardial fistula due to a disparate group of conditions have been reported in the literature. ${ }^{1,5,6,7,8,9}$ Amongst the causes described are thoraco-abdominal trauma, ${ }^{3,10}$ systemic infections, previous gastro-oesophageal surgery, ${ }^{2,10,11}$ adjacent inflammatory foci and benign gastric ulcers. ${ }^{1,3,12}$ Of the reported cases, 10 have been attributed to underlying gastric malignancy. ${ }^{1}$ In this report we present a fatal case of gastropericardial fistula arising from the transdiaphragmatic invasion of a malignant gastric ulcer.

\section{Case report}

A 36-year-old man presented to the Medical Service at King Edward VIII
Hospital in Durban with a one month history of loss of appetite and weight, progressive breathlessness, swelling of the legs and dysphagia. On presentation he was found to be emaciated with a tinge of jaundice, left supraclavicular lymphadenopathy, pitting oedema of the lower limbs and in congestive cardiac failure. Chest examination revealed fine crackles along both lung bases; auscultation of the heart revealed a pericardial friction rub. Abdominal examination revealed no abnormalities.

An admission chest $\mathrm{x}$-ray revealed features of cardiac failure and the patient was initially managed for a pericarditis and cardiac failure. The haemoglobin was $10.2 \mathrm{~g} / \mathrm{dl}$ and white cell count was $12.4 \times 10^{9}$. The urea and electrolytes revealed a mildly elevated serum urea. ECG changes were in keeping with cardiac failure and a pericarditis. Over the ensuing two days no improvement was noted in the patient's general condition and the dysphagia persisted. A barium swallow performed showed a normal oesophagus. However a fistula between the lesser curve of the stomach and the pericardial cavity was easily demonstrated (Figure 1). Delayed radiographs depicted a large pneumopericardium (Figure 2). The radiological features of the stomach suggested a malignant process. Subsequently at gastroscopy, a shrunken stomach with a malignant appearing ulcer along the lesser curve of the stomach was noted and biopsied. The fistula was not identified. Shortly after the gastroscopy the patient's condition rapidly deteriorated and he demised without any definitive treatment. Histological assessment of the gastroscopic biopsy revealed an adenocarcinoma of the stomach. 
A new giant has emerged in South Africa's R300 million p.a. medical equipment servicing market with the launch of a GE Macmed joint venture targeting a R70 million turnover in its first year by breaking with tradition to launch servicing of competing brands of healthcare equipment.

"General Electric (GE) took a strategic decision to launch multivendor servicing of medical equipment South Africa in partnership with a well established local company," says Christopher Austin, GE Medical Systems General Sales Manager for southern Africa. "The pooling of resources with the listed Macmed group combines the international strength and

knowhow of General Electric with Macmed's accumulated local knowledge and market penetration in South Africa and other African countries."

\section{STRONG GROWTH}

Austin predicts strong growth for multi-vendor servicing offered by GE Macmed.

"The entire healthcare industry in South Africa is under enormous pressure to contain and even reduce costs. Since we are able to show that multi-vendor servicing can lead to substantial savings in operating costs, we are bullish about growth prospects locally.

"In fact, local healthcare groups, which together operate 215 hospitals, have already expressed interest in the new service. The government's 360 hospitals also present significant opportunities."

Donald McArthur, founder of the multi-million rand Macmed group, says the joint venture provides excellent growth prospects in a market ripe for an innovative approach.

"Multi-vendor servicing provided by GE has proved an unqualified success in the United States. Improved control and management of service costs is an attractive proposition to local healthcare facility operators."
The majority shareholding in GE Macmed is held by GE's Medical Systems division.

GE Macmed - which at launch date will have more than 100 employees - will also sell a range of high technology equipment, including diagnostic imaging systems, and vascular and nuclear medical equipment.

Austin says that the joint venture will provide a vehicle for GE Medical Systems to improve penetration of markets in southern Africa and other African countries with GE's range of diagnostic imaging equipment. The existing Macmed distribution network will be utilised.

DIAGNOSTIC IMAGING GE Macmed will be in the top three suppliers of diagnostic imaging equipment in South Africa, worth an estimated R160 million pa. The company's nationwide servicing capability will cover equipment ranging from imaging systems to incubators, defribulators, dialysis machines and operating tables.

GE pioneered multi-vendor servicing in the United States several years ago.

The Comprecare (TM) service concept has since undergone rapid growth with more than 1100 hospitals in America and Europe now under contract with GE Medical Systems.

\section{REINFORCED}

\section{COMMITMENT}

Mike Hendry, National Executive of General Electric Southern Africa, says the joint venture further reinforces GE's commitment to southern Africa and "supports our undertaking to generate R2bn in industrial, commercial and economic benefits to the local economy. It also provides a strong avenue for growth into the rest of Africa."

General Electric (GE) of the US is the number one company in the world in terms of market capitalisation, with revenues in excess of US\$90 billion.

\section{Hour Call Centre}

GE Macmed maintains a 24 hour call centre to provide a high level of services to its entire customer base nationwide. Highly trained medical technical staff are available at all times to assist clients with queries. Technical staff are able to provide support and assist with solving technical problems. Where applicable, technical staff are despatched to customer sites. In appropriate instances, contact is made with the five InSite facilities run by General Electric Medical Systems around the world for assistance with remote diagnostics and corrective action. GE Macmed's 24 Hour Call Centre can be contacted at (011) 3156625 .

\section{InSite - Advanced Remote Maintenance}

The highly successful Insite service run by GE Medical Systems provides remote diagnostics and software corrections in minutes for a wide range of GE imaging systems. In instances where a problem cannot be resolved remotely, a field engineer is despatched to the customer site having been provided with a preliminary diagnosis. He is thus able to rectify a problem rapidly by confirming the diagnosis on site and replacing the part with a replacement which he drew from stores prior to visiting the customer'spremises. 
Here's your complimentary easy-to-use dial to enable you to identify GE Macmed's area of focus in southern Africa and beyond.

Remove the dial from the page and use it at your leisure. Don't forget to keep it in a safe place for future reference.

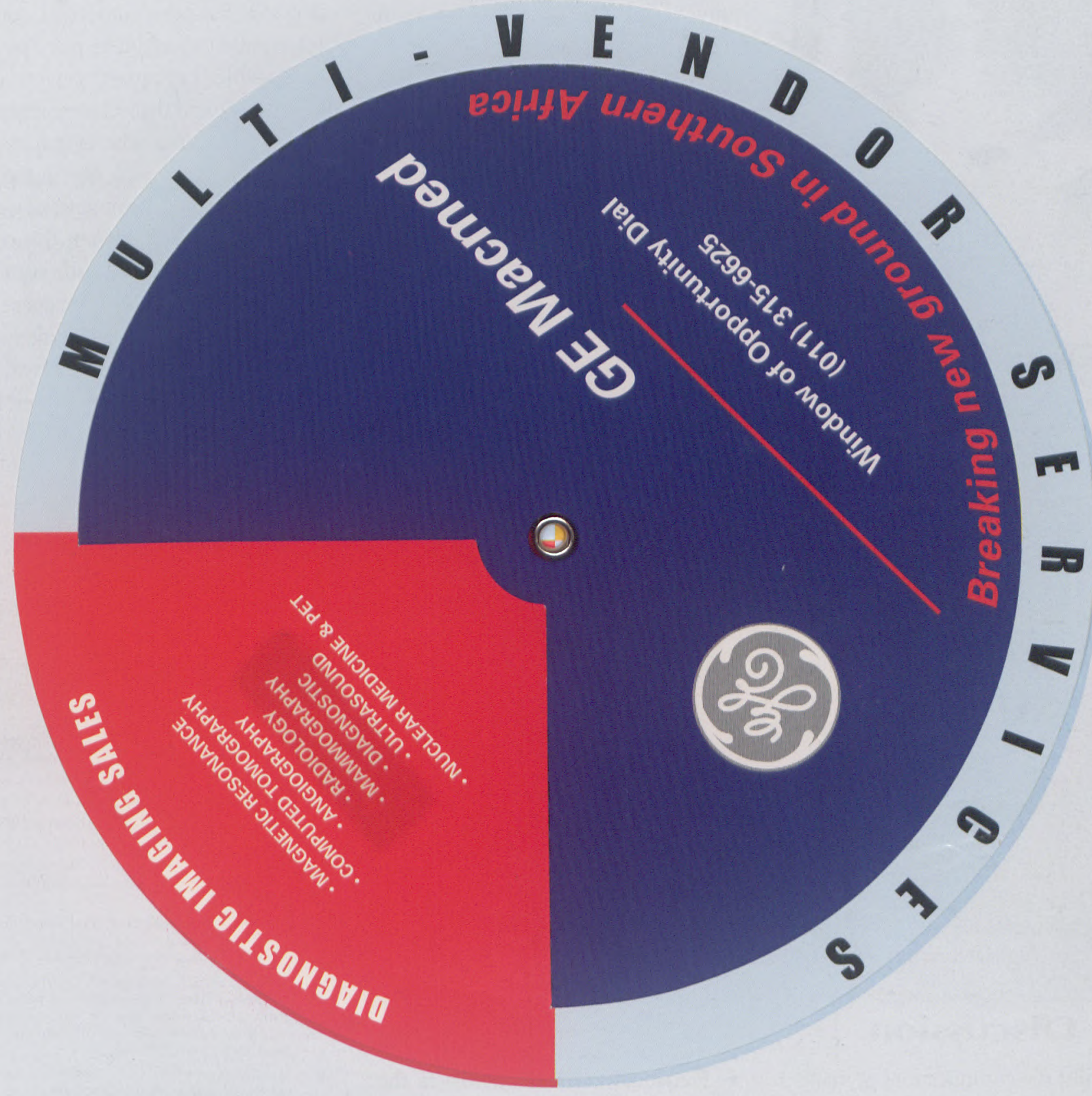

GE Macmed 
from page 15

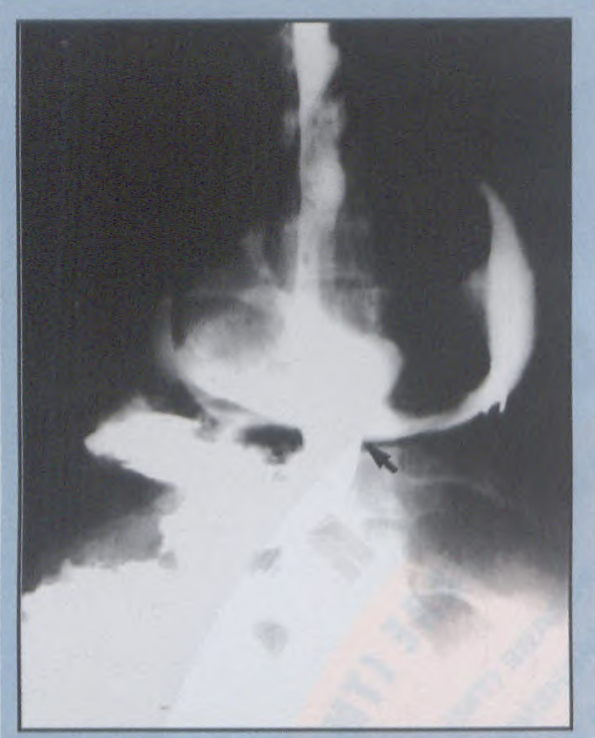

Figure 1: Gastropericardial fistula (arrow) with barium outlining the pericardial sac.

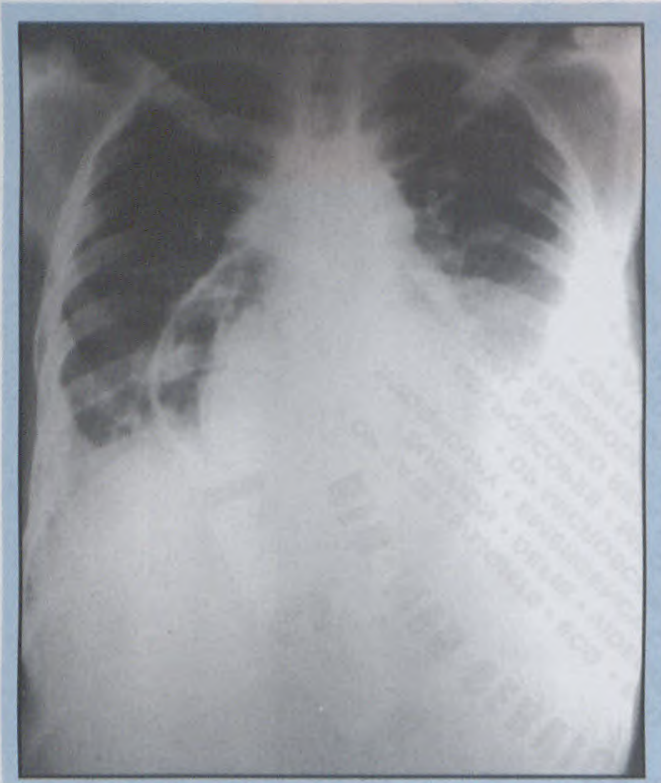

Figure 2: Chest radiograph demonstrating pneumopericardium.

\section{Discussion}

Whilst the complications of malignant gastric ulcers are usually predictable, only awareness of the rare and invariably fatal gastropericardial fistula occurring as a result of this condition will result in its early recognition and treatment. The anatomical proximity of the lesser curve of the stomach to the pericardium readily predisposes to fistulation between these two struc- tures. However, because of the strength of the fibrous central tendon, such fistulation is rare. In our patient it could be postulated that adhesion of the lesser curve of the stomach to the diaphragm with subsequent trans-serosal extension of the tumour and invasion of the central tendon gave rise to the fistula. The patient probably presented just prior to complete fistulation which would explain the absence of a pneumopericardium on the admission chest $\mathrm{x}$-ray. It may be speculated that the gastroscopy actually exaggerated the pneumopericardium and hastened the patient's demise.

Chest pain, dyspnoea, cyanosis and shock with a pericardial friction rub or occasionally loud bruit or bruit de moulin are the cardinal symptoms and signs of pericarditis associated with a gastropericardial fistula. ${ }^{3,10}$ Occasionally these patients present with cardiac tamponade ${ }^{3,7}$ as a result of the pneumopericardium which maybe complicated by an empyaema if the diagnosis is delayed. ${ }^{3,10,11}$ In the presence of a pneumopericardium, a chest $\mathrm{x}$-ray is usually diagnostic. However a contrast study is indicated to identify the site of the fistula and sometimes as in our patient, to assist with the pathological diagnosis.

Gossot $^{2}$ identified three features common to gastropericardial fistulae irrespective of the underlying causes previously mentioned:

- Frequency of hiatus hernia in the genesis of these lesions; $2,7,9,13$ either from an ulcer, oesophagitis or herniated stomach or from surgical complications

- Need for aggressive treatment

- High mortality - $68 \%$

Regardless of the aetiology, the reported mortality from this condition ranges between 68 and $85 \% .{ }^{1,2}$ These extremely ill patients should be aggressively resuscitated, admitted to an intensive care unit, given inotropic support and antibiotics and ventilatory support should be considered. ${ }^{3}$ Once the diagnosis has been confirmed, surgical intervention should take place as soon as possible. Letoquart ${ }^{1}$ reviewed 52 cases and found that 42 were related to benign conditions. The overall mortality was $85 \%$, although one in two patients survived if urgent surgery was resorted to. The prognosis in this condition may be enhanced with aggressive resuscitation, pericardial drainage and appropriate gastro-intestinal surgery. ${ }^{1,2,3,10}$ Although the risks associated with surgery in these patients are extremely high, they are less likely to result in mortality which is almost invariable in the conservatively managed patient.

\section{References}

1. Letoquart JP, Fasquel JL, L'Huillier JP, Babatasi G, Gruel Y, Lauvin R, Mambrini A. Les fistules gastropericardiques. Revue de la litterature a propos d'un cas original. J de Chir 1990; 127 (1): 6-12

2. Gossot D, Mariambourg G, Assens P, Sarfati E, Celerier M, Dubost C. Fistule gastro-pericardique. Complication tardive d'une cure de hernie hiatale. J de Chir 1986 123 (12): 704-8.

3. Nicolaou N, Katz G, Conlan AA. Gastropericardia fistula presenting as acute cardiac tamponade. $S$ Afr Med $J$ 1984; 65 (2): $51-2$.

Hallin, cited by Pick L. Z Klin Med 1891; 26: 452.

5. Edwards JR, Humeniuk V. Gastropericardial Fistula. Austr and New Zeal J Surg 1996; 66 (4): 257-9.

6. Schneider F, Schenk M, Tempe JD, Thiry L. Spontaneous gastropericardial fistula. Ann Emerg Med 1995; 26 (3): 394.

Prabhudev N, Ramesh B, Prabhakar, Rao AS. "Gastropericardial fistula" presenting as cardiac tamponade. J Assoc Phys India 1994; 42 (2): 157-8.

8. Salo JA, Heikkila L, Nemlander A, Lindahl H, Louhimo I, Mattila S. Barrett's oesophagus and perforation of gastric tube ulceration into the pericardium : a late complication after reconstruction of oesophageal atresia. Ann Chir et Gynae 1995; 84 (1): 92-4

9. Mukai M, Nimomiya T, Ocji N, Hamada M. An 80 year old female with pneumopericardium due to gastric perforation. Nippon Ronen Igakkai Zassini - Jap J Geriatr 1995; 32 (2): 123-7.

10. Gleser RA. A case of gastropericardial fistula. SAfr Med J 1973; 39: 1799-801.

11. Ikard RW, Jacobs JK. Gastropericardial fistula and pericardial abscess : unusual complications of subphrenic abscess following Nissen fundoplication. South Med $1974 ; 67$ (1): 17-9

12. Ghahremani GG, Yaghmai S, Brooks JW, Hutton CF. Pneumopericardium due to transdiaphragmatic perforation of a gastric ulcer. Am J Digest Dis 1976; 21 (7): $586-91$

13. Monro JL, Nicholls RJ, Hately W, Murray RS, Flavell G. Gastropericardial fistula - a complication of hiatus hernia. Brit J Surg 1974; 61 (6): 445-7. 